\title{
openheart Cause of death in patients with atrial fibrillation admitted to French hospitals in 2012: a nationwide database study
}

\author{
Laurent Fauchier, ${ }^{1,2}$ Adeline Samson, ${ }^{3}$ Gwendoline Chaize, ${ }^{4}$ \\ Anne-Françoise Gaudin, ${ }^{5}$ Alexandre Vainchtock, ${ }^{4}$ Cécile Bailly, ${ }^{5}$ \\ Francois-Emery Cotté ${ }^{5}$
}

To cite: Fauchier L,

Samson A, Chaize G, et al. Cause of death in patients with atrial fibrillation admitted to French hospitals in 2012: a nationwide database study. Open Heart 2015;2:e000290. doi:10.1136/openhrt-2015000290

- Additional material is available. To view please visit the journal online (http://dx. doi.org/10.1136/openhrt2015-000290).

Received 4 May 2015 Revised 29 June 2015 Accepted 26 August 2015

\section{(a) CrossMark}

${ }^{1}$ Service de Cardiologie et Laboratoire

d'Electrophysiologie

Cardiaque, Pôle Cœur

Thorax; asculaire, Centre

Hospitalier Universitaire

Trousseau, Tours, France

${ }^{2}$ Faculté de Médecine,

Université François Rabelais,

Tours, France

${ }^{3}$ Paris-Dauphine University,

Paris, France

${ }^{4}$ HEVA, Lyon, France

${ }^{5}$ Bristol-Myers Squibb,

Rueil-Malmaison, France

Correspondence to Dr Laurent Fauchier; Ifau@med.univ-tours.fr

\section{ABSTRACT}

Objective: Most patients with atrial fibrillation (AF) have risk factors and coexisting conditions that increase their mortality risk. We performed a cause-ofdeath analysis to identify predictors of mortality in hospitalised patients with AF in France.

Methods and results: In this retrospective, population-based cross-sectional study, the Programme de médicalisation des systèmes d'information was used to identify 533044 adults with a diagnosis of $\mathrm{AF}$ or atrial flutter hospitalised for any reason in France from January through December 2012. Stepwise multivariable analyses were performed to identify determinants of mortality. The mean age was $78.0 \pm 11.4$ years, $47.1 \%$ were women, and the mean $\mathrm{CHA}_{2} \mathrm{DS}_{2}-\mathrm{VASc}$ score was $4.0 \pm 1.8$. During hospitalisation, $9.4 \%$ ( $n=50165)$ of the patients died, $34 \%$ due to a cardiovascular event, most often heart failure (16.6\%), stroke/transient ischaemic attack/ systemic embolism $(9.8 \%)$ or vascular or ischaemic disease (4.0\%). The strongest predictors of overall death were age $\geq 75$ years (OR $2.57,95 \% \mathrm{Cl} 2.47$ to 2.68), renal failure ( $\mathrm{OR} 1.85,95 \% \mathrm{Cl} 1.81$ to 1.89 ), cancer (OR $1.81,95 \% \mathrm{Cl} 1.78$ to 1.85 ) and lung disease (OR $1.58,95 \% \mathrm{Cl} 1.55$ to 1.62 ).

Conclusions: Cardiovascular events were the most common cause of death, occurring in one-third of patients, in this comprehensive study of hospitalised patients with AF. Despite the high risk of stroke in this population, only $10 \%$ died from stroke/transient ischaemic attack/systemic embolism. The strongest predictors of overall death were non-cardiovascular. Physicians should be encouraged to focus on preventable serious and disabling cardiovascular events (such as stroke) as well as on potentially fatal non-cardiovascular comorbidities.

\section{INTRODUCTION}

Atrial fibrillation (AF) is the most common chronic cardiac rhythm disorder, with a prevalence of between $1 \%$ and $2 \%$ in the general population. ${ }^{1}$ Between 600000 and 1 million people in France are estimated to have $\mathrm{AF}^{2}$ and the prevalence is rising. ${ }^{3}{ }^{4} \mathrm{AF}$

\section{KEY QUESTIONS}

What is already known about this subject?

- Most patients with atrial fibrillation (AF) have risk factors and coexisting conditions that increase their mortality risk, but the mode of death in patients with $\mathrm{AF}$ is poorly understood.

What does this study add?

- Cardiovascular events were the most common cause of death (34\% of cases) in this comprehensive study of hospitalised patients with AF.

- Ten per cent of the patients died from stroke/ transient ischaemic attack/systemic embolism.

- The strongest predictors of overall death were non-cardiovascular: age $\geq 75$ years, renal failure, cancer and lung disease.

How might this impact on clinical practice?

- Physicians in charge of the management of patients with AF should be encouraged to focus not only on preventable serious and disabling cardiovascular events (such as stroke) but also on other potentially fatal non-cardiovascular comorbidities.

is associated with a 1.5-fold mortality risk in men and a 2-fold risk in women, after adjustment for associated cardiovascular conditions. $^{5}$ The Women's Health Study, in an analysis of 34722 initially healthy women, showed that new-onset AF is independently associated with cardiovascular, noncardiovascular and all-cause mortality. ${ }^{6} \mathrm{AF}$ is also associated with worse clinical outcomes in many cardiovascular disease states. $^{7-9}$ Patients with $\mathrm{AF}$ are at fivefold increased risk of ischaemic or haemorrhagic stroke. ${ }^{10}$ The severity of the stroke is greater compared with strokes unrelated to $\mathrm{AF}^{7}$ and the 30-day mortality rate is higher. ${ }^{7}$ An analysis from a French national database estimated that $21.6 \%$ of patients with $\mathrm{AF}$ who are hospitalised due to an ischaemic or haemorrhagic stroke die during hospitalisation. ${ }^{11}$ 
Most patients with AF have cardiovascular risk factors and coexisting conditions that increase their mortality risk, ${ }^{46}$ but the mode of death in patients with $\mathrm{AF}$ is poorly understood. Predictors of mortality were identified using data from the Randomized Evaluation of Long-Term Anticoagulant Therapy (RE-LY) trial, which compared dabigatran with vitamin $\mathrm{K}$ antagonists in $>18000$ patients with $\mathrm{AF}^{12}$ The strongest predictors of cardiac death were heart failure, previous myocardial infarction, abnormal conduction and reduced renal function. Stroke accounted for only $11.4 \%$ of cardiovascular deaths. The applicability of the RE-LY study findings, conducted within the confines of a selected clinical trial population (in which oral anticoagulation was systematically used), to patients with AF treated in everyday clinical practice, is uncertain. There is, therefore, a need to better understand the AF population in order to identify specific interventions that could reduce the mortality risk associated with this increasingly prevalent arrhythmia.

The aims of this study were twofold: to identify the characteristics of patients hospitalised with AF in France; and to perform a cause-of-death analysis to identify predictors of overall mortality, and mortality due to heart failure, ischaemic stroke and intracranial haemorrhage.

\section{METHODS}

BALZAC (Burden of cArdiovascuLar hospitaliZations in patients with Atrial fibrillation in FranCe) was a retrospective, population-based cross-sectional study. We used data from the Programme de médicalisation des systèmes d'information (PMSI), which comprises national comprehensive databases that record diagnoses and procedures for all day care and inpatient stays in private and public hospitals in France. PMSI has previously been used to study patients with stroke,${ }^{13}$ myocardial infarction ${ }^{14}$ and $\mathrm{AF}^{2}$

This study was conducted in accordance with International Society for Pharmacoepidemiology Guidelines for Good Pharmacoepidemiology Practices and applicable regulatory requirements. The study was approved by the Commission Nationale Informatique et Liberté (National Commission for Data Protection and the Liberties), the independent National ethical committee protecting human rights in France, including those of patients. As a retrospective observational analysis from a national database, patient informed consent was not obtained. Procedures for data collection and management were approved by the Conseil National de l'Informatique et des Libertés, which ensures that all medical information is kept confidential and anonymous.

The study population comprised adults ( $\geq 18$ years) with a diagnosis of $\mathrm{AF}$ or atrial flutter (see online supplementary table S1 for the International Classification of Disease 10th edition (ICD-10) codes) coded in the principal diagnosis (ie, the health problem that justified admission to hospital, and coded at discharge), the related diagnosis (ie, potential chronic disease or health state during hospital stay) or the significantly associated diagnosis (ie, comorbidity or associated complication), who were hospitalised for any reason from 1 January to 31 December 2012. Patient information (demographics, comorbid conditions, medical history and death during hospitalisation, if it occurred in 2012) is described using data collected in their hospital records since 1 January 2007.

Individualised risk stratification was performed retrospectively using the $\mathrm{CHA}_{2} \mathrm{DS}_{2}$-VASc (Cardiac failure or dysfunction, Hypertension, Age $\geq 75$ years (Doubled), Diabetes, Stroke (Doubled)-Vascular disease, Age 65-74 years and Sex category (Female) $)^{15}$ score for stroke and the HAS-BLED (Hypertension, Abnormal renal/liver function, Stroke, Bleeding history or predisposition, Labile international normalised ratio (INR), Elderly (>65 years), Drugs/alcohol concomitantly) ${ }^{16}$ score for bleeding. As not all components of the HAS-BLED score were available, a modified version ${ }^{17}$ (excluding labile INR and antithrombotic drug therapy) is presented. Patients who died in hospital (including in a rehabilitation centre) were identified through their discharge summary, and each in-hospital death was attributed to one cause exclusively (ie, the principal diagnosis for the hospitalisation when death occurred).

\section{Statistical analysis}

Categorical variables are described using counts and percentages, and continuous quantitative variables as means and SDs or medians (IQRs), as appropriate. Clinical parameters of patients with AF alive and dead at discharge for any reasons were compared, as well as for a patient with AF suffering from three specific types of event: heart failure, ischaemic stroke and intracranial haemorrhage. Intergroup differences were assessed using the $\chi^{2}$ test for categorical variables and Student's $t$ test or the Mann-Whitney $\mathrm{U}$ test for continuous variables. To identify predictors of death, multiple logistic regression analyses based on a forward stepwise method adjusted for age, sex and all clinical variables with $\mathrm{p}<0.05$ in the univariate analysis were performed. ORs and $95 \%$ CIs were calculated. In all analyses, a value of $\mathrm{p}<0.05$ was considered statistically significant. To further take into account a possible sex and age period interaction, we performed interaction tests. All analyses were performed using SAS software V.9.2 (Cary, North Carolina, USA).

\section{RESULTS}

\section{Hospitalised patients with AF}

In France, in 2012, 533044 patients were hospitalised with $\mathrm{AF}$ as the principal, related or associated diagnosis. The mean number of hospitalisations per patient was 1.53 (1.64 for patients who died and 1.51 for those who survived), leading to a total of 813168 hospital stays. The mean age was $78.0 \pm 11.4$ years, $47.1 \%$ were women, the 
mean $\mathrm{CHA}_{2} \mathrm{DS}_{2}$-VASc score was $4.0 \pm 1.8$ and the mean HAS-BLED score was 2.2 \pm 1.1 . Half of the patients $(50.2 \%, \mathrm{n}=267681)$ were hospitalised for a cardiovascular reason (table 1). The cardiac diagnoses leading to hospitalisation were, in decreasing frequency, dysrhythmia $(22.5 \%)$, heart failure $(18.3 \%)$, vascular and ischaemic diseases (7.1\%), stroke/transient ischaemic attack (TIA)/systemic embolism (SE) $(6.8 \%)$ and haemorrhage (1.3\%) (table 1).

During hospitalisation, $9.4 \% \quad(n=50165)$ of the patients died. These patients were older than those who survived, had a higher prevalence of comorbid conditions and risk factors, and were at higher risk of a stroke or a bleed according to their $\mathrm{CHA}_{2} \mathrm{DS}_{2}$-VASc and

Table 1 Principal reasons for hospitalisation (patients may have been hospitalised on more than one occasion in 2012)

\begin{tabular}{|c|c|}
\hline Reason & N (\%) \\
\hline \multicolumn{2}{|c|}{$\begin{array}{l}\text { Patients with atrial fibrillation in } 2012 \text { in France } \\
(n=533044)\end{array}$} \\
\hline Cardiac dysrhythmia & $119930(22.5)$ \\
\hline Heart failure & $97622(18.3)$ \\
\hline Lung disease & $63750(12.0)$ \\
\hline Digestive disease & $37864(7.1)$ \\
\hline Vascular or ischaemic diseases & $37670(7.1)$ \\
\hline Stroke/TIA/SE & $36320(6.8)$ \\
\hline Rheumatological disease & $26810(5.0)$ \\
\hline Cancer & 25894 (4.9) \\
\hline Ophthalmological condition & $11401(2.1)$ \\
\hline Haemorrhage & 7013 (1.3) \\
\hline Other & $117015(22.0)$ \\
\hline Urology/nephrology & $27193(5.1)$ \\
\hline Orthopaedics and rheumatology & $23087(4.3)$ \\
\hline Neurology & $19658(3.7)$ \\
\hline Endocrinology & $15303(2.9)$ \\
\hline Haematology & $15030(2.8)$ \\
\hline Digestive disorders & $12213(2.3)$ \\
\hline Infectious diseases & $5364(1.0)$ \\
\hline \multicolumn{2}{|c|}{ Patients with AF who died in hospital $(n=50$ 165) } \\
\hline Lung disease & 8967 (17.9) \\
\hline Heart failure & $8316(16.6)$ \\
\hline Stroke/TIA/SE & $4901(9.8)$ \\
\hline Cancer & $3521(7.0)$ \\
\hline Digestive disease & $3091(6.2)$ \\
\hline Vascular/ischaemic disease & $2016(4.0)$ \\
\hline Cardiac dysrhythmia & $1117(2.2)$ \\
\hline Haemorrhage & $716(1.4)$ \\
\hline Rheumatological disease & $665(1.3)$ \\
\hline Ophthalmological condition & $12(0.2)$ \\
\hline Other & $10038(20.0)$ \\
\hline Urology/nephrology & 1545 (3.1) \\
\hline Orthopaedics and rheumatology & $1351(2.7)$ \\
\hline Neurology & $1034(2.1)$ \\
\hline Infectious diseases & $920(1.8)$ \\
\hline Endocrinology & $866(1.7)$ \\
\hline Haematology & $683(1.4)$ \\
\hline Digestive disorders & $406(0.8)$ \\
\hline
\end{tabular}

HAS-BLED scores (table 2). The three most common reasons for hospitalisation in the patients who died were for a lung condition, heart failure or stroke/TIA/SE (table 1). Thirty-four per cent $(n=17066)$ of the in-hospital deaths were due to a cardiovascular event (table 3), most commonly heart failure $(16.6 \%)$, stroke/ TIA/SE (9.8\%) and vascular or ischaemic disease $(4.0 \%)$ (table 3 ).

The overall median length of hospitalisation was 6 (IQR 2-12) days (6 (2-12) days among survivors and 8 (3-16) days among those who died). The median lengths of hospitalisation were 8 (3-15) days for patients who had a cardiovascular death and 9 (3-17) days for non-cardiovascular death.

\section{Determinants of death}

Age $\geq 75$ years was the strongest determinant of death on multivariable analysis in the overall population. This was followed by non-cardiovascular factors such as renal failure, cancer, lung disease, age 65-74 years, neurological disease, alcohol-related diagnosis and anaemia (figure 1). The only major cardiovascular predictor was heart failure, which was associated with a $26 \%$ increased risk of death. Female gender and vascular disease were marginally associated with risk of death, whereas history of thyroid disease and hypertension were associated with a lower risk of death. Significant interactions were found between age and four variables (cancer, renal failure, alcohol-related diagnoses and lung disease), and between sex and anaemia (all $\mathrm{p}<0.0001$; see online supplementary table S2), with the interaction between age and cancer having the greatest magnitude (interaction test 834, $\mathrm{p}<0.0001)$, but the interaction did not drastically change the conclusions of the multivariable analysis (see online supplementary table S2). When focusing multivariable analysis on the 17066 cardiovascular deaths, determinants were similar, with the exception of cancer, neurological disease, alcohol-related diagnoses and anaemia, which were no longer significant (figure 2). Significant interaction was found between age and renal failure (interaction test 256, $\mathrm{p}<0.0001$ ).

Among the 95655 patients with AF hospitalised for heart failure (see online supplementary table S3), 8.7\% $(n=8316)$ died. Variables associated with in-hospital death in this population included older age, cancer, liver or renal failure, lung or neurological diseases, anaemia, history of heart failure and valvular disease/ surgery (table 4). Thyroid disease and other ischaemic heart disease were associated with a lower risk of death.

Substantially fewer patients $(n=19909)$ were hospitalised for an ischaemic stroke (see online supplementary table S4), of whom $13.1 \%(n=2614)$ died during hospitalisation. Factors associated with death after an ischaemic stroke were advanced age ( $\geq 65$ years), female sex, lung diseases, peripheral artery disease, renal failure and heart failure (table 5).

Patients hospitalised with intracranial haemorrhage (see online supplementary table S5) were at much 
Table 2 Characteristics of patients hospitalised with AF in France in 2012 (all $p<0.001$ )

\begin{tabular}{|c|c|c|}
\hline & $\begin{array}{l}\text { Patients discharged } \\
\text { alive } \\
n=482879\end{array}$ & $\begin{array}{l}\text { Patients who died during } \\
\text { hospitalisation } \\
\mathrm{n}=50165\end{array}$ \\
\hline Age, mean (SD), years & $77.6 \pm 11.5$ & $82.3 \pm 9.3$ \\
\hline Women, \% & 47.1 & 47.6 \\
\hline $\begin{array}{l}\text { Cumulative length of stay in hospital (or to death), median } \\
\text { (IQR), median (IQR), days }\end{array}$ & $9.0(4.0-17.0)$ & $14.0(6.0-28.0)$ \\
\hline \multicolumn{3}{|l|}{ Comorbidities*, \% } \\
\hline Alcohol-related diagnosis & 5.9 & 7.5 \\
\hline Anaemia & 22.6 & 35.5 \\
\hline Cancer in preceding 5 years & 17.8 & 30.2 \\
\hline Diabetes mellitus & 24.0 & 26.7 \\
\hline Hypertension & 69.9 & 73.0 \\
\hline Inflammatory disease & 9.5 & 11.9 \\
\hline Liver failure & 4.3 & 8.8 \\
\hline Lung disease & 21.3 & 34.2 \\
\hline Neurological disease & 9.9 & 15.6 \\
\hline Renal failure & 21.2 & 39.1 \\
\hline Thyroid disease & 13.3 & 14.3 \\
\hline \multicolumn{3}{|l|}{ Cardiovascular history (\%) } \\
\hline Stroke & 7.9 & 9.6 \\
\hline Ischaemic & 6.2 & 7.3 \\
\hline Haemorrhagic & 1.1 & 1.5 \\
\hline Unspecified & 1.6 & 2.2 \\
\hline Major haemorrhage $†$ & 2.4 & 3.3 \\
\hline Intracranial & 0.5 & 0.7 \\
\hline Gastrointestinal & 0.9 & 1.5 \\
\hline Any severe bleeding & 1.1 & 1.5 \\
\hline Systemic embolism & 3.0 & 4.4 \\
\hline Transient ischaemic attack & 3.0 & 3.3 \\
\hline Vascular disease & 17.2 & 22.4 \\
\hline Myocardial infarction & 7.8 & 9.6 \\
\hline Peripheral artery disease & 9.4 & 13.4 \\
\hline Occlusion of precerebral artery or other arterial disorder & 4.2 & 5.7 \\
\hline Other ischaemic heart disease & 21.7 & 25.6 \\
\hline Symptoms of AF leading to hospitalisation & 7.4 & 6.5 \\
\hline Heart failure & 28.3 & 41.8 \\
\hline Cardiac dysrhythmia & 7.6 & 8.3 \\
\hline Abnormal cardiac conduction & 16.0 & 18.9 \\
\hline Valvular disease/surgery & 13.5 & 17.3 \\
\hline Mitral stenosis & 0.8 & 0.9 \\
\hline Accidental falls & 9.5 & 15.4 \\
\hline \multicolumn{3}{|l|}{ Risk scores } \\
\hline $\mathrm{CHA}_{2} \mathrm{DS}_{2}$-VASc, mean (SD) & $4.0(1.8)$ & $4.6(1.6)$ \\
\hline $\mathrm{CHA}_{2} \mathrm{DS}_{2}$-VASc, median (IQR) & $4.0(3.0-5.0)$ & $5.0(4.0-6.0)$ \\
\hline Score $0-3, \%$ & 38.6 & 24.3 \\
\hline Score 4-6, \% & 53.8 & 63.9 \\
\hline Score $7-9, \%$ & 7.6 & 11.8 \\
\hline HAS-BLED, mean (SD) & $2.1(1.1)$ & $2.6(1.1)$ \\
\hline HAS-BLED, median (IQR) & $2.0(1.0-3.0)$ & $2.0(2.0-3.0)$ \\
\hline Score $0-2, \%$ & 68.2 & 50.4 \\
\hline Score $\geq 3 \%$ & 31.8 & 49.6 \\
\hline
\end{tabular}

${ }^{*}$ From the International Classification of Disease 10th edition (ICD-10) codes (see online supplementary table S1).

†Bleeding leading to a hospitalisation: intracranial haemorrhage, gastrointestinal haemorrhage, other major bleeding.

$\mathrm{AF}$, atrial fibrillation; $\mathrm{CHA}_{2} \mathrm{DS}_{2}-\mathrm{VASc}$, Cardiac failure or dysfunction, Hypertension, Age $\geq 75$ (Doubled), Diabetes, Stroke (Doubled)-Vascular disease, Age 65-74 and Sex category (Female); HAS-BLED, Hypertension, Abnormal renal/liver function, Stroke, Bleeding history or predisposition, Labile international normalised ratio (INR), Elderly, Drugs/alcohol concomitantly.

higher risk of in-hospital death $(18.8 \%)$ compared to patients with heart failure $(\mathrm{p}<0.05)$. Predictors of death included age $\geq 75$ years, lung diseases and valvular disease/surgery (table 6). Previous intracranial haemorrhage decreased the risk of death after a new episode. 
Table 3 Cause of death in patients admitted with atrial fibrillation

\begin{tabular}{lr}
\hline & N (\%) \\
\hline All deaths & $50165(100.0)$ \\
Non-cardiovascular death & $33099(66.0)$ \\
Cardiovascular death & $17066(34.0)$ \\
Heart failure & $8316(16.6)$ \\
Stroke, transient ischaemic attack, & $4901(9.8)$ \\
systemic embolism & \\
Ischaemic stroke & $2614(5.2)$ \\
Haemorrhagic stroke & $1334(2.7)$ \\
Unspecified & $294(0.6)$ \\
Transient ischaemic attack & $69(0.1)$ \\
Systemic embolism & $590(1.2)$ \\
Vascular or ischaemic diseases & $2016(4.0)$ \\
Cardiac dysrhythmia & $1117(2.2)$ \\
Haemorrhage & $716(1.4)$ \\
Intracranial & $335(0.7)$ \\
Gastrointestinal & $130(0.3)$ \\
Other bleed & $251(0.5)$ \\
\hline
\end{tabular}

\section{DISCUSSION}

This study was based on data from over half a million hospitalised patients with AF in France (of an estimated 600000 to $1000000^{2}$ ), of whom nearly $10 \%$ died. The most common cause of death was a fatal cardiovascular event, occurring in $34 \%$ of patients. Despite the high mean $\mathrm{CHA}_{2} \mathrm{DS}_{2}$-VASc score $(4.6 \pm 1.6)$, only $9.8 \%$ of the deceased patients had a fatal stroke or SE.

The patients in our study were older than those in the international GARFIELD-AF registry ${ }^{18}(78.0 \pm 11.4$ vs $70.2 \pm 11.2$ years, respectively), with a greater percentage of women $(47.1 \%$ vs $43.2 \%)$ and a higher mean
$\mathrm{CHA}_{2} \mathrm{DS}_{2}$-VASc score $(4.0 \pm 1.8$ vs $3.2 \pm 1.6)$. These dissimilarities are likely to be due to differences in the study populations: while the GARFIELD-AF enrolled patients newly diagnosed with $\mathrm{AF}$ at risk of stroke across the spectrum of treatment settings, our study concerned hospitalised patients with AF. Our population more closely resembles that in the nationwide US Outcomes Registry for Better Treatment of Atrial Fibrillation (ORBIT-AF), in which the median age was 75 years (IQR 6782 years), the mean $\mathrm{CHA}_{2} \mathrm{DS}_{2}$-VASc score was $3.9 \pm 1.8$, $29.4 \%$ had diabetes and $32.5 \%$ had heart failure; however, the rates of hypertension $(83.0 \%)$ and previous myocardial infarction (15.8\%) were higher than in our study. ${ }^{19}$

Conversely, patients in clinical trials are subject to selection bias and do not, therefore, reflect the spectrum of patients treated in practice. ${ }^{20}$ Women and the elderly have been under-represented in phase III studies involving non-vitamin $\mathrm{K}$ antagonists, whereas diabetes, hypertension, heart failure and previous myocardial infarction were more prevalent than in the registry settings, largely due to the selection of patients with $\mathrm{AF}$ with one or more additional risk factors for stroke. ${ }^{18} 21$ Therefore, national population-based studies such as BALZAC - while subject to confounding-provide more accurate information about the profiles of patients with $\mathrm{AF}$ treated in routine clinical practice in their respective countries, and should provide more precise insights into the factors associated with hospital death in patients encountered in practice.

In this analysis of patients with AF, most of whom had a significant associated comorbid condition, 1 in 10 died during hospitalisation; this is in agreement with the results from other nationwide studies. ${ }^{52}$ The rate may
Figure 1 Determinants of death on multivariable analysis (all $\mathrm{p}<0.0001)$. ${ }^{*}$ Reference is absent disease or condition.

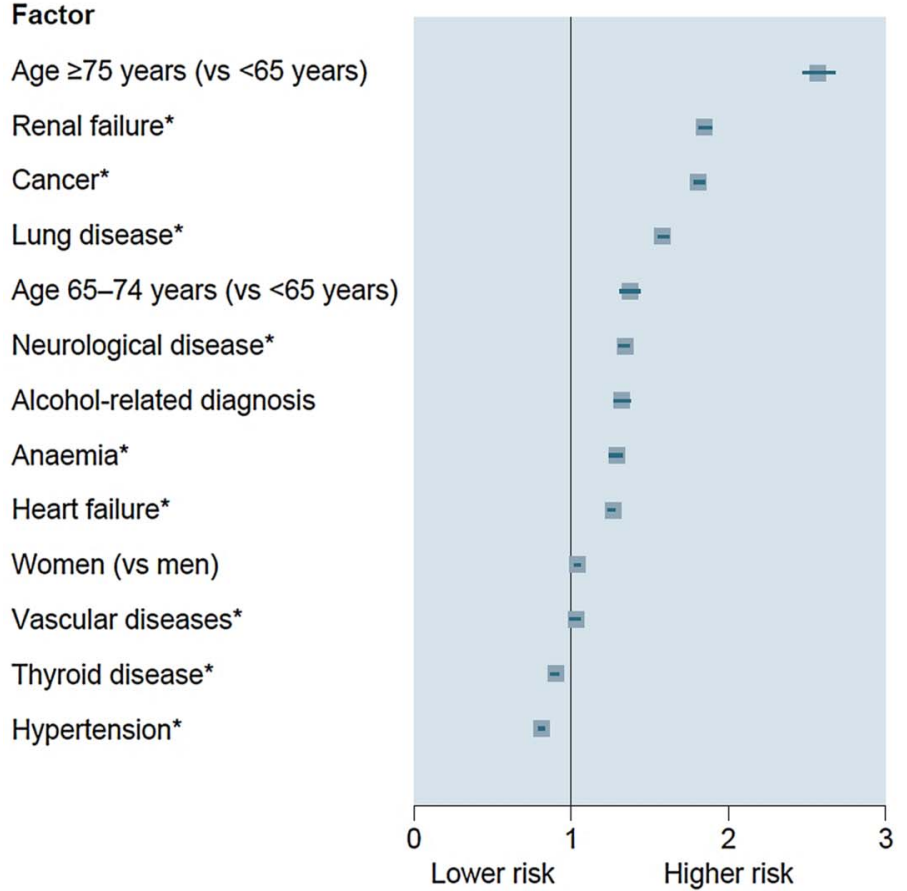

Odds ratio $(95 \% \mathrm{Cl})$

$2.57(2.47-2.68)$

$1.85(1.81-1.89)$

$1.81(1.78-1.85)$

$1.58(1.55-1.62)$

$1.37(1.31-1.44)$

$1.34(1.30-1.37)$

1.32 (1.27-1.37)

1.29 (1.26-1.32)

1.26 (1.23-1.28)

1.04 (1.02-1.06)

1.03 (1.00-1.06)

$0.90(0.87-0.92)$

$0.81(0.79-0.83)$ 
Figure 2 Multivariable analyses of risk factors for overall cardiovascular death (all $\mathrm{p}<0.0001)$. ${ }^{*}$ Reference is absent disease or condition.
Factor

Age $\geq 75$ years ( $v s<65$ years)

Renal failure*

Age 65-74 years (vs $<65$ years)

Heart failure*

Lung disease*

Vascular diseases*

Women (vs men)

Thyroid disease*

Hypertension*

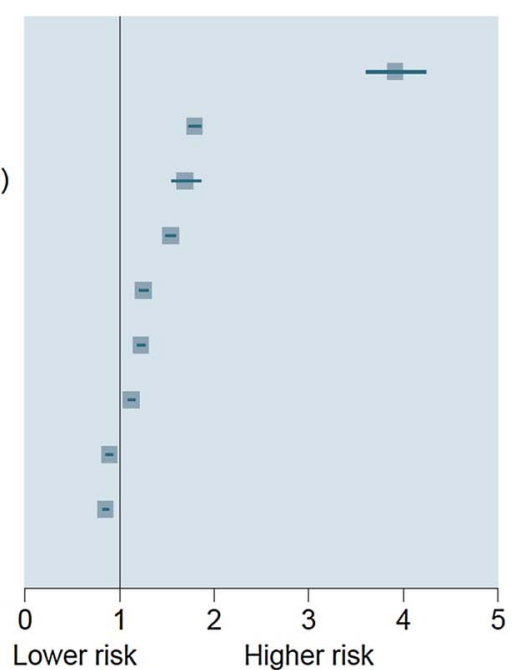

Odds ratio $(95 \% \mathrm{Cl})$

$3.91(3.61-4.24)$

$1.79(1.73-1.86)$

$1.69(1.55-1.86)$

$1.54(1.49-1.59)$

$1.25(1.21-1.30)$

$1.22(1.18-1.27)$

$1.12(1.09-1.16)$

$0.89(0.85-0.93)$

$0.85(0.82-0.89)$ appear higher than that reported by Patel $e t a t^{23}$ in an analysis from the US Nationwide Inpatient Sample (hospital mortality rate $1 \%$, rising to $2 \%$ for those aged $\geq 80$ years); however, the rate increased to $10 \%$ in the subgroup of patients with a history of heart failure, which is indirectly similar to our finding. The rate of cardiovascular deaths in hospitalised patients with $\mathrm{AF}$ $(34.0 \%)$ could be viewed as being somewhat similar to the rates reported for the general population in the USA $(31.3 \%)^{24}$ and in France $(27.5 \%) .^{25}$ As such, AF could simply reflect cardiovascular ageing, and would therefore be representative of general population trends rather than being specific to those with $\mathrm{AF}$. It is, however, unrealistic to compare our patients to the general population, as hospitalised patients with $\mathrm{AF}$ are primarily elderly individuals with coexisting conditions

Table 4 Univariate and multivariable analysis of risk factors for death after heart failure

\begin{tabular}{|c|c|c|c|c|c|}
\hline \multirow[b]{2}{*}{ Deaths due to heart failure } & \multicolumn{3}{|c|}{ Univariate analysis } & \multicolumn{2}{|c|}{ Multivariable analysis } \\
\hline & $\begin{array}{l}\text { Alive patients } \\
\text { n (\%) }\end{array}$ & $\begin{array}{l}\text { Dead patients } \\
\text { n (\%) }\end{array}$ & p Value & OR $(95 \% \mathrm{Cl})$ & p Value \\
\hline Patients & 87339 (91.3) & $8316(8.7)$ & - & & \\
\hline \multicolumn{6}{|l|}{ Age group, years } \\
\hline$<65$ & 7755 (8.9) & $254(3.1)$ & - & Ref & - \\
\hline $65-74$ & $12774(14.6)$ & $655(7.9)$ & $<0.0001$ & $1.47(1.27$ to 1.70$)$ & $<0.0001$ \\
\hline$\geq 75$ & $66810(76.5)$ & 7407 (89.1) & $<0.0001$ & 3.07 (2.70 to 3.49$)$ & $<0.0001$ \\
\hline Female sex & $44343(50.8)$ & $4300(51.7)$ & 0.10 & - & - \\
\hline \multicolumn{6}{|l|}{ Comorbidity } \\
\hline Anaemia & 23449 (26.8) & 2887 (34.7) & $<0.0001$ & $1.11(1.05$ to 1.17$)$ & $<0.0001$ \\
\hline Cancer & 12483 (14.3) & $1496(18.0)$ & $<0.0001$ & 1.17 (1.10 to 1.22$)$ & $<0.0001$ \\
\hline Liver failure & $4333(5.0)$ & $692(8.3)$ & $<0.0001$ & 1.68 (1.54 to 1.83$)$ & $<0.0001$ \\
\hline Lung disease & 22935 (26.3) & 2688 (32.3) & $<0.0001$ & 1.16 (1.11 to 1.22$)$ & $<0.0001$ \\
\hline Neurological diseases & $7307(8.4)$ & 1073 (12.9) & $<0.0001$ & 1.32 (1.23 to 1.42$)$ & $<0.0001$ \\
\hline Renal failure & 26947 (30.9) & $3886(46.7)$ & $<0.0001$ & 1.60 (1.52 to 1.68$)$ & $<0.0001$ \\
\hline Thyroid disease & $13264(15.2)$ & $1363(16.4)$ & 0.03 & $0.93(0.87$ to 0.98$)$ & 0.014 \\
\hline Inflammatory disease & $8733(10.0)$ & $1003(12.1)$ & $<0.0001$ & - & - \\
\hline \multicolumn{6}{|l|}{ Medical history } \\
\hline Heart failure & $39152(44.8)$ & $4916(59.1)$ & $<0.0001$ & $1.40(1.33$ to 1.47$)$ & $<0.0001$ \\
\hline Valvular disease/surgery & 23447 (26.8) & 2575 (31.0) & $<0.0001$ & 1.08 (1.03 to 1.14$)$ & 0.003 \\
\hline Systemic embolism & 2920 (3.3) & $351(4.2)$ & $<0.0001$ & - & - \\
\hline Peripheral artery disease & $10147(11.6)$ & $1163(14.0)$ & $<0.0001$ & - & - \\
\hline Occlusion* & $4532(5.2)$ & 493 (5.9) & $<0.0001$ & - & - \\
\hline AF symptoms & $7090(8.1)$ & $588(7.1)$ & $<0.0001$ & - & - \\
\hline Abnormal cardiac conduction & 19619 (22.5) & $2248(27.0)$ & $<0.0001$ & - & - \\
\hline Intracranial haemorrhage $†$ & $394(0.6)$ & $50(0.6)$ & 0.06 & - & - \\
\hline
\end{tabular}


Table 5 Univariate and multivariable analyses of risk factors for death after an ischaemic stroke

\begin{tabular}{|c|c|c|c|c|c|}
\hline \multirow[b]{2}{*}{$\begin{array}{l}\text { Ischaemic stroke } \\
\mathrm{N}=19909\end{array}$} & \multicolumn{3}{|c|}{ Univariate analysis } & \multicolumn{2}{|c|}{ Multivariable analysis } \\
\hline & $\begin{array}{l}\text { Alive patients } \\
\mathrm{n}(\%)\end{array}$ & $\begin{array}{l}\text { Dead patients } \\
\text { n (\%) }\end{array}$ & p Value & OR $(95 \% \mathrm{Cl})$ & p Value \\
\hline Patients & 17295 (86.9) & 2614 (13.1) & - & - & - \\
\hline \multicolumn{6}{|l|}{ Age group, years } \\
\hline$<65$ & $2648(15.3)$ & $212(8.1)$ & - & Ref. & - \\
\hline $65-74$ & $1394(8.1)$ & $66(2.5)$ & 0.0003 & $1.62(1.22$ to 2.15$)$ & 0.0009 \\
\hline$\geq 75$ & $13253(76.6)$ & $2336(89.4)$ & $<0.0001$ & 3.30 (2.56 to 4.26$)$ & $<0.0001$ \\
\hline Female sex & $9780(56.5)$ & $1612(61.7)$ & $<0.0001$ & 1.18 (1.08 to 1.29$)$ & 0.0002 \\
\hline \multicolumn{6}{|l|}{ Comorbidity } \\
\hline Lung disease & 2920 (16.9) & $784(30.0)$ & $<0.0001$ & 1.95 (1.77 to 2.15$)$ & $<0.0001$ \\
\hline Peripheral artery disease & $1178(6.8)$ & $270(10.3)$ & $<0.0001$ & $1.32(1.14$ to 1.53$)$ & 0.0002 \\
\hline Renal failure & $2561(14.8)$ & $570(21.8)$ & $<0.0001$ & 1.30 (1.16 to 1.44$)$ & $<0.0001$ \\
\hline Anaemia & 2535 (14.7) & $499(19.1)$ & $<0.0001$ & - & - \\
\hline Cancer & 2035 (11.8) & $361(13.8)$ & 0.0028 & - & - \\
\hline Myocardial infarction & $987(5.7)$ & $195(7.5)$ & 0.0004 & - & - \\
\hline Neurological diseases & 2139 (12.4) & $412(15.8)$ & $<0.0001$ & - & - \\
\hline Thyroid disease & $1976(11.4)$ & 338 (12.9) & 0.025 & - & - \\
\hline \multicolumn{6}{|l|}{ Medical history } \\
\hline Heart failure & $3306(19.1)$ & 739 (28.3) & $<0.0001$ & $1.28(1.16$ to 1.41$)$ & $<0.0001$ \\
\hline Other ischaemic heart disease & 2641 (15.3) & 494 (18.9) & $<0.0001$ & - & - \\
\hline Abnormal cardiac conduction & $1986(11.5)$ & $374(14.3)$ & $<0.0001$ & - & - \\
\hline Valvular disease/surgery & $1557(9.0)$ & $309(11.8)$ & $<0.0001$ & - & - \\
\hline Hypertension & 12475 (73.7) & $1927(72.1)$ & 0.09 & - & - \\
\hline Systemic embolism* & $451(2.6)$ & $101(3.9)$ & 0.003 & - & - \\
\hline
\end{tabular}

(whether cardiovascular, such as stroke, or noncardiovascular, such as cancer and lung disease) that place them at increased risk of dying.

\section{Independent predictors of mortality}

Older age ( $\geq 75$ years) was the strongest predictor of overall death in our study, similar to the findings in the
Framingham Heart Study in patients with new-onset AF ((HR) for stroke or death $2.13,95 \%$ CI 1.89 to 2.40 per 10 -year increase).$^{26}$ Age as a predictor of mortality was followed by renal failure, cancer and lung diseases. In contrast, in a post hoc analysis of deaths from the RE-LY trial database, which reported an annual mortality rate of $3.84 \%,{ }^{12}$ non-fatal major haemorrhage, non-fatal

Table 6 Univariate and multivariable analyses of risk factors for death after an intracranial haemorrhage

\begin{tabular}{|c|c|c|c|c|c|}
\hline \multirow[b]{2}{*}{$\begin{array}{l}\text { Intracranial haemorrhage } \\
\mathrm{N}=1785\end{array}$} & \multicolumn{3}{|c|}{ Univariate analysis } & \multicolumn{2}{|c|}{ Multivariable analysis } \\
\hline & $\begin{array}{l}\text { Alive patients } \\
\mathrm{n}(\%)\end{array}$ & $\begin{array}{l}\text { Dead patients } \\
\mathrm{n}(\%)\end{array}$ & p Value & OR (95\% Cl) & p Value \\
\hline Patients & $1450(81.2)$ & $335(18.8)$ & & & \\
\hline \multicolumn{6}{|l|}{ Age group, years } \\
\hline$<65$ & $185(12.8)$ & $25(7.5)$ & - & - & - \\
\hline $65-74$ & $86(5.9)$ & $7(2.1)$ & 0.26 & - & - \\
\hline$\geq 75$ & 1179 (81.3) & 303 (90.4) & 0.004 & $2.19(1.48$ to 3.24$)$ & $<0.0001$ \\
\hline Female sex & $603(41.6)$ & $138(41.2)$ & 0.90 & - $\quad$ - & - \\
\hline \multicolumn{6}{|l|}{ Comorbidity } \\
\hline Lung diseases & $252(17.4)$ & $87(26.0)$ & 0.0003 & 1.69 (1.27 to 2.24$)$ & 0.0003 \\
\hline Anaemia & $302(20.8)$ & 89 (26.6) & 0.022 & - & - \\
\hline Peripheral artery disease & $112(7.7)$ & $40(11.9)$ & 0.013 & - & - \\
\hline Renal failure & $283(19.5)$ & $87(26.0)$ & 0.009 & - & - \\
\hline \multicolumn{6}{|l|}{ Medical history } \\
\hline Intracranial haemorrhage & $118(8.1)$ & $14(4.2)$ & 0.014 & $0.47(0.26$ to 0.83$)$ & 0.009 \\
\hline Valvular disease/surgery & $174(12.0)$ & $60(17.9)$ & 0.004 & 1.58 (1.14 to 2.19$)$ & 0.006 \\
\hline Heart failure & $388(26.8)$ & 119 (35.5) & 0.001 & - & - \\
\hline AF symptoms & $86(5.9)$ & $29(8.7)$ & 0.07 & - & - \\
\hline
\end{tabular}


stroke, heart failure and reduced renal function were the strongest predictors of overall mortality. ${ }^{12}$ These differences are not surprising, taking into consideration the profiles of the two populations. All of the patients in the present study were hospitalised and were considerably older than those selected for the RE-LY trial ${ }^{12}$ (mean 78.0 vs 71.5 years), which may in part explain the greater representation of women; and participants who died were on average 8 years older $(82.3 \pm 9.3$ years in the present study vs $73.7 \pm 9.4$ years in RE-LY). The patients who died in RE-LY also had higher prevalence of diabetes mellitus ( $30.9 \%$ vs $26.7 \%)$, hypertension $(76.7 \%$ vs $73.0 \%)$ and heart failure $(47.8 \%$ vs $41.8 \%)$, but they also had a much lower prevalence of cancer $(12.7 \%$ vs $30.2 \%$ ). Consequently, the causes of death show substantial differences, with a $34 \%$ rate of cardiovascular death in the present study compared with a $61.4 \%$ rate in RE-LY. ${ }^{12}$

In our study, thyroid disease and hypertension were protective against death. It is likely that patients with thyroid disease or hypertension were being monitored closely by their physicians and were receiving appropriate therapies that lowered their risk of death. They may also have been more aware of their increased risk and were adhering to guidance about adopting a healthy lifestyle. Indeed, only $10 \%$ of the patients died from thromboembolic causes despite a high $\mathrm{CHA}_{2} \mathrm{DS}_{2}$-VASc score, and it is possible that these patients were being closely monitored for their anticoagulation status. Our findings are supported by other studies, in which various treatments and medications (including statins, $\beta$-blockers, oral anticoagulant use, ventricular pacing), as well as hypertension, were protective against mortality. ${ }^{12} 27$

\section{Cause-specific cardiovascular mortality}

The strongest predictor of heart failure death was age $\geq 75$ years. Several comorbid conditions were associated with death, including renal failure, liver, lung and neurological diseases, along with cancer and anaemia. A history of heart failure and valvular disease/surgery were also independent predictors. As for overall mortality, thyroid disease was protective in our analysis, and may be a proxy for the use of appropriate therapies and better continuity of care, which lowered their risk of death.

Independent predictors of fatal ischaemic stroke included older age, lung disease and renal failure. Cardiovascular-related predictors were peripheral artery disease and heart failure. Female sex was also predictive of fatal stroke, as shown in other studies in which women were at higher risk of stroke when compared with men. ${ }^{28} 29$ This finding lends further support to the inclusion of female gender in the $\mathrm{CHA}_{2} \mathrm{DS}_{2}$-VASc score. $^{15}$

Age $>65$ years, lung diseases, valvular disease/surgery and anaemia were associated with fatal intracranial haemorrhage. Previous intracranial haemorrhage was protective against a fatal intracranial haemorrhage, and may reflect 'survivors' of this event, who have a higher probability of survival due to their increased awareness of the symptoms and ongoing management. These findings contrast with the RE-LY study, in which non-fatal stroke during follow-up was the only significant predictor of haemorrhage-related death. ${ }^{12}$

Interestingly, some of the predictors were the same for all three causes of death, but some were more specific, and these findings are among the new insights from our analysis.

\section{Limitations}

As a retrospective analysis, the study is subject to the normal limitations of such studies. The cohort comprises hospitalised patients, who are at higher risk than nonhospitalised patients. Second, the analysis is limited to deaths that occurred during hospitalisation, and the results cannot be generalised to patients who died before hospitalisation or after discharge. However, French data show that hospital deaths account for $66 \%$ of all deaths in patients aged 70-80 years, similar to the mean age of our population. ${ }^{30}$ Our study, therefore, provides important insights into the reasons why patients with AF die.

The study data were collected retrospectively and are also, by definition, subject to classification bias. Some minor diagnoses may have been under-reported in the database because of a lack of incentive for the hospital to exhaustively report every case, while others may have been misclassified. However, this registry has been adopted by the health authorities as the principal index for budget allocation in French public hospitals, and the quality of information in the PMSI databases has improved dramatically over recent years. Indeed, patients from the present study showed a prevalence of chronic diseases and antecedents close to those reported in other observational studies. ${ }^{18}{ }^{31}$ Furthermore, the reliability of the PMSI data has been assessed, ${ }^{32} 33$ and this information has been used to study patients with stroke, ${ }^{13}$ myocardial infarction ${ }^{34}$ and $\mathrm{AF}^{2}$ The results may not be generalisable to the general population since a known comorbidity with AF or atrial flutter, and perhaps oral anticoagulation and other underlying cardiac conditions, may have led to a lower threshold for hospital admission. No information was available for medications, in particular anticoagulation or medications for heart failure, in this national database. This limitation does not alter the results on cause of death in patients with $\mathrm{AF}$, but the availability of cardiovascular treatments, including oral anticoagulant therapies for stroke prevention and treatments for heart failure, would be of major interest for future research on predictors of death in this specific population. The rate of anticoagulant use in France at the time this study was conducted is estimated to be approximately $80 \%$, according to registries, ${ }^{31}{ }^{35}$ but the rate is likely to be lower in unselected patients. Finally, our analysis 
included every AF diagnosis, irrespective of whether it was the primary reason for hospitalisation or a coexisting condition.

\section{CONCLUSIONS}

Cardiovascular events were the most common cause of death in patients hospitalised for AF in France, occurring in $34 \%$ of patients. Despite the high risk of stroke in this population, only $9.8 \%$ died from stroke/TIA/SE. Optimal management is necessary, including the use of evidence-based cardiac medications, to reduce the risk of death in hospitalised patients with AF.

Acknowledgements Writing support was provided by Sophie Rushton-Smith, $\mathrm{PhD}$.

Contributors All the authors contributed to the study design and interpretation of results, and reviewed and approved the manuscript prior to submission. F-EC wrote the first manuscript draft and performed all analyses.

Funding The work was supported by Bristol-Myers Squibb France and Pfizer France.

Competing interests $L F, G C$ and $A V$ received consulting fees from Bristol-Myers Squibb and Pfizer. AS received grants from Bristol-Myers Squibb. A-FG, CB and F-EC are employees of Bristol-Myers Squibb.

Ethics approval The study was approved by the Commission Nationale Informatique et Liberté (National Commission for Data protection and the Liberties.

Provenance and peer review Not commissioned; externally peer reviewed.

Open Access This is an Open Access article distributed in accordance with the Creative Commons Attribution Non Commercial (CC BY-NC 4.0) license, which permits others to distribute, remix, adapt, build upon this work noncommercially, and license their derivative works on different terms, provided the original work is properly cited and the use is non-commercial. See: http:// creativecommons.org/licenses/by-nc/4.0/

\section{REFERENCES}

1. Wilke $T$, Groth $A$, Mueller $S$, et al. Incidence and prevalence of atrial fibrillation: an analysis based on 8.3 million patients. Europace 2013;15:486-93.

2. Charlemagne A, Blacher J, Cohen A, et al. Epidemiology of atrial fibrillation in France: extrapolation of international epidemiological data to France and analysis of French hospitalization data. Arch Cardiovasc Dis 2011;104:115-24.

3. Stefansdottir H, Aspelund T, Gudnason V, et al. Trends in the incidence and prevalence of atrial fibrillation in Iceland and future projections. Europace 2011;13:1110-17.

4. Piccini JP, Hammill BG, Sinner MF, et al. Incidence and prevalence of atrial fibrillation and associated mortality among Medicare beneficiaries, 1993-2007. Circ Cardiovasc Qual Outcomes 2012;5:85-93.

5. Benjamin EJ, Wolf PA, D'Agostino RB, et al. Impact of atrial fibrillation on the risk of death: the Framingham Heart Study. Circulation 1998;98:946-52.

6. Conen D, Chae CU, Glynn RJ, et al. Risk of death and cardiovascular events in initially healthy women with new-onset atrial fibrillation. JAMA 2011;305:2080-7.

7. Marini C, De Santis F, Sacco S, et al. Contribution of atrial fibrillation to incidence and outcome of ischemic stroke: results from a population-based study. Stroke 2005;36:1115-19.

8. Camm AJ, Kirchhof P, Lip GY, et al, European Heart Rhythm Association, European Association for Cardio-Thoracic Surgery, ESC Committee for Practice Guidelines. Guidelines for the management of atrial fibrillation: the Task Force for the Management of Atrial Fibrillation of the European Society of Cardiology (ESC). Europace 2010;12:1360-420.
9. Goto S, Bhatt DL, Rother J, et al. Prevalence, clinical profile, and cardiovascular outcomes of atrial fibrillation patients with atherothrombosis. Am Heart J 2008;156:855-63, 63 e2.

10. Kirchhof $\mathrm{P}$, Auricchio $\mathrm{A}, \mathrm{Bax} \mathrm{J}$, et al. Outcome parameters for trials in atrial fibrillation: executive summary. Eur Heart $J$ 2007;28:2803-17.

11. Cotte FE, Chaize G, Kachaner I, et al. Incidence and cost of stroke and hemorrhage in patients diagnosed with atrial fibrillation in France. J Stroke Cerebrovasc Dis 2014;23:e73-83.

12. Marijon E, Le Heuzey JY, Connolly S, et al. Causes of death and influencing factors in patients with atrial fibrillation: a competing-risk analysis from the randomized evaluation of long-term anticoagulant therapy study. Circulation 2013;128:2192-201.

13. Chevreul K, Durand-Zaleski I, Gouepo A, et al. Cost of stroke in France. Eur J Neurol 2013;20:1094-100.

14. Tuppin P, Neumann A, Danchin N, et al. Evidence-based pharmacotherapy after myocardial infarction in France: adherence-associated factors and relationship with 30-month mortality and rehospitalization. Arch Cardiovasc Dis 2010;103:363-75.

15. Lip GY, Nieuwlaat $R$, Pisters $R$, et al. Refining clinical risk stratification for predicting stroke and thromboembolism in atrial fibrillation using a novel risk factor-based approach: the euro heart survey on atrial fibrillation. Chest 2010;137:263-72.

16. Pisters R, Lane DA, Nieuwlaat R, et al. A novel user-friendly score (HAS-BLED) to assess 1-year risk of major bleeding in patients with atrial fibrillation: the Euro Heart Survey. Chest 2010;138:1093-100.

17. Friberg L, Rosenqvist M, Lip GY. Evaluation of risk stratification schemes for ischaemic stroke and bleeding in 182678 patients with atrial fibrillation: the Swedish Atrial Fibrillation cohort study. Eur Heart J 2012;33:1500-10.

18. Kakkar AK, Mueller I, Bassand JP, et al. Risk profiles and antithrombotic treatment of patients newly diagnosed with atrial fibrillation at risk of stroke: perspectives from the international, observational, prospective GARFIELD registry. PLOS ONE 2013;8: e63479.

19. Fosbol EL, Holmes DN, Piccini JP, et al. Provider specialty and atrial fibrillation treatment strategies in United States community practice: findings from the ORBIT-AF registry. J Am Heart Assoc 2013;2: e000110.

20. Rothwell PM. Commentary: external validity of results of randomized trials: disentangling a complex concept. Int $J$ Epidemiol 2010;39:94-6.

21. Connolly SJ, Eikelboom J, Joyner C, et al. Apixaban in patients with atrial fibrillation. N Engl J Med 2011;364:806-17.

22. Olesen JB, Lip GY, Hansen ML, et al. Validation of risk stratification schemes for predicting stroke and thromboembolism in patients with atrial fibrillation: nationwide cohort study. BMJ 2011;342: d124.

23. Patel NJ, Deshmukh A, Pant S, et al. Contemporary trends of hospitalization for atrial fibrillation in the United States, 2000 through 2010: implications for healthcare planning. Circulation 2014;129:2371-9.

24. Mozaffarian D, Benjamin EJ, Go AS, et al. Heart disease and stroke statistics-2015 update: a report from the American Heart Association. Circulation 2015;131:e29-e322.

25. Aouba A, Eb M, Rey G, et al. Mortality data in France: the main causes of death in 2008 and trends since 2000. Bull Épidémiol hebdomadaire 2011;22:249-55.

26. Wang TJ, Massaro JM, Levy D, et al. A risk score for predicting stroke or death in individuals with new-onset atrial fibrillation in the community: the Framingham Heart Study. JAMA 2003;290:1049-56.

27. Girerd N, Pibarot P, Daleau P, et al. Statins reduce short- and long-term mortality associated with postoperative atrial fibrillation after coronary artery bypass grafting: impact of postoperative atrial fibrillation and statin therapy on survival. Clin Cardiol 2012;35:430-6.

28. Dagres N, Nieuwlaat R, Vardas PE, et al. Gender-related differences in presentation, treatment, and outcome of patients with atrial fibrillation in Europe: a report from the Euro Heart Survey on Atrial Fibrillation. J Am Coll Cardiol 2007;49:572-7.

29. Fang MC, Singer DE, Chang $Y$, et al. Gender differences in the risk of ischemic stroke and peripheral embolism in atrial fibrillation: the AnTicoagulation and Risk factors In Atrial fibrillation (ATRIA) Study. Circulation 2005;112:1687-91.

30. Gisquet E, Aouba A, Aubry R, et al. [Where do we die in France? Analysis of death certificates (1993-2008)]. Bull Épidémiol hebdomadaire 2012;48:547-51.

31. Cohen A, Dallongeville J, Durand-Zaleski I, et al. Characteristics and management of outpatients with history of or current atrial fibrillation: 
the observational French EPHA study. Arch Cardiovasc Dis 2010;103:376-87.

32. Couris CM, Polazzi S, Olive F, et al. Breast cancer incidence using administrative data: correction with sensitivity and specificity. J Clin Epidemiol 2009;62:660-6.

33. Chantry AA, Deneux-Tharaux C, Cans C, et al. Hospital discharge data can be used for monitoring procedures and intensive care related to severe maternal morbidity. J Clin Epidemiol 2011;64:1014-22.
34. Lorgis L, Cottenet J, Molins G, et al. Outcomes after acute myocardial infarction in HIV-infected patients: analysis of data from a French nationwide hospital medical information database. Circulation 2013;127:1767-74

35. Le Heuzey JY, Ammentorp B, Darius $\mathrm{H}$, et al. Differences among western European countries in anticoagulation management of atrial fibrillation. Data from the PREFER IN AF registry. Thromb Haemost 2014;111:833-41. 